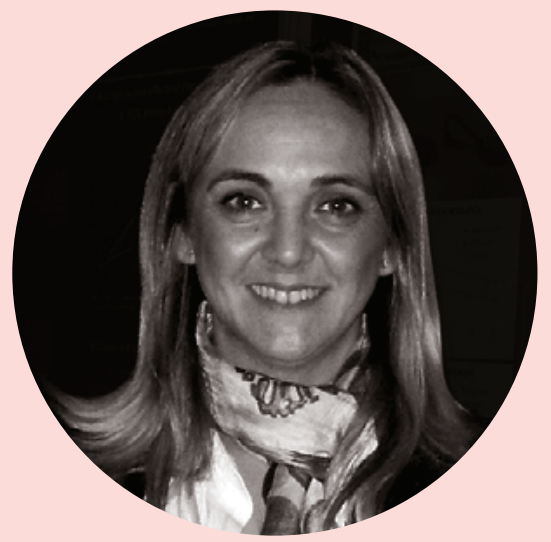

\title{
Alimentos con ciencia
}

\section{La profesora de la UMH María José Frutos investiga para obtener productos innovadores y saludables}

La responsable del Grado en Ciencia y Tecnología de los Alimentos de la UMH investiga para mejorar productos comestibles con el uso de compuestos bioactivos o probióticos. María José Frutos explica que una dieta completa asegura los compuestos bioactivos necesarios para el organismo. "El salmón, por ejemplo, nos aporta Omega 3 y los polifenoles están presentes en todas las frutas y verduras", señala. Pero, a juicio de la profesora, la forma de vida actual se aleja del ideal de dieta equilibrada. En este sentido, la doctora señala que se toman muchos alimentos faltos de fibra o muy pocos vegetales. "Por eso no está de más disponer de alimentos funcionales", asegura. La investigadora aboga por un consumo responsable sin ocupar posiciones extremas: "No es necesario llenar el carro de la compra de alimentos funcionales ni prescindir de ellos por escepticismo".

\section{Nutrición y salud}

El equipo en el que trabaja la profesora de la UMH cuenta con dos líneas de trabajo relacionadas con los alimentos funcionales. Por una

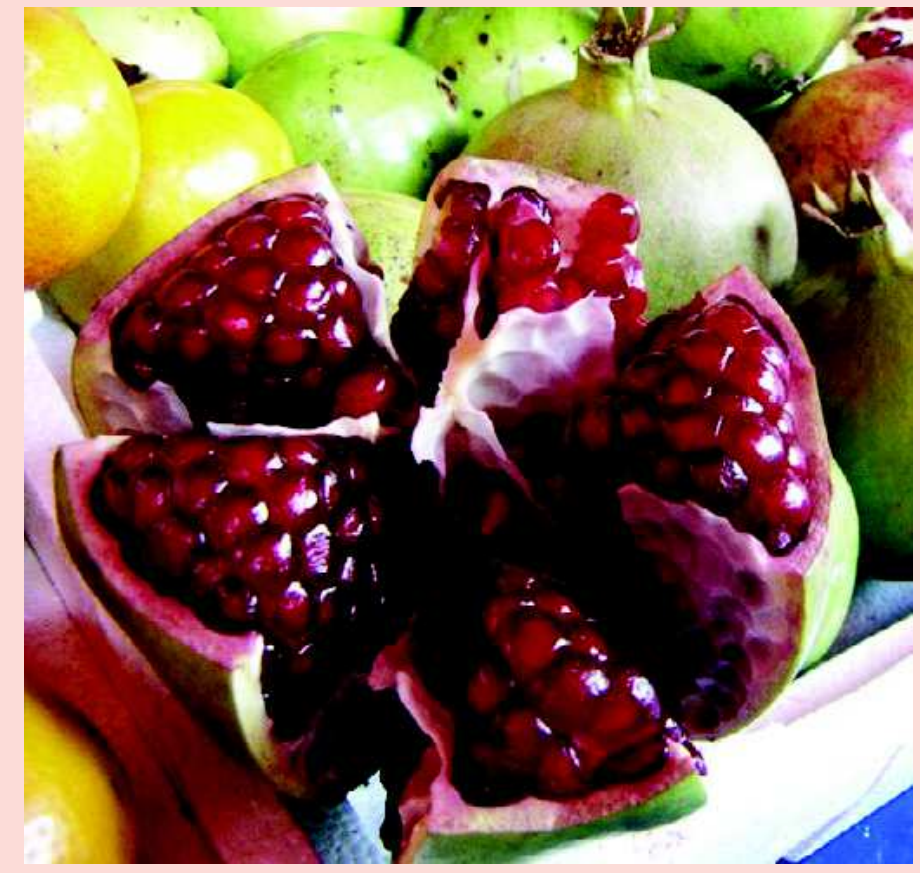

parte, el grupo desarrolla alimentos probióticos con bacterias beneficiosas para la salud. Por otra, persiguen obtener comestibles con compuestos bioactivos, procedentes de vegetales, como los polifenoles, que poseen propiedades antioxidantes y saludables.

Entre las fuentes de compuestos bioactivos procedentes de plantas, el equipo ha participado en un proyecto europeo en el que se han empleado residuos de producción del aceite de lino -con alto contenido en fitoestrógenos- para introducirlos en alimentos como el pan o la pizza. Según la investigadora, el grupo utiliza fuentes vegetales de las que se dispone de extensa bibliografía sobre sus beneficios para la salud. "Como, por ejemplo, los antocianos, que son polifenoles datos científicos sobre alimentos, nutrición y salud. Para la investigadora del Grupo de Calidad y Seguridad Alimentaria de la UMH María José Frutos Fernández, los alimentos funcionales suponen un avance para mejorar algunas carencias ligadas a la forma de consumo actual y al acelerado ritmo de vida. con propiedades antioxidantes presentes en vegetales y responsables de los tonos azules y rojos de la granada, la fresa, la ciruela o la berenjena”, precisa.

La profesora de la UMH señala que se han centrado en determinar el efecto que tiene el procesado de los alimentos estudiados sobre su estabilidad: "Analizamos si el almacenamiento o el tratamiento térmico de un producto puede conllevar la degradación de los compuestos beneficiosos para la salud o a la pérdida de viabilidad de los microorganismos".

Los beneficios de los probióticos presentes en el yogur son conocidos entre los consumidores, pero los investigadores de la UMH proponen alternativas a los lácteos que también contienen microorganismos saludables. La doctora Frutos señala que, junto con la profesora Estefanía Valero, poseen una patente mundial para el desarrollo de gelatinas con microorganismos beneficiosos. En esta misma línea, la docente comenta que el equipo ha creado zumos fermentados con bacterias probióticas: "Tratamos de cono- > 


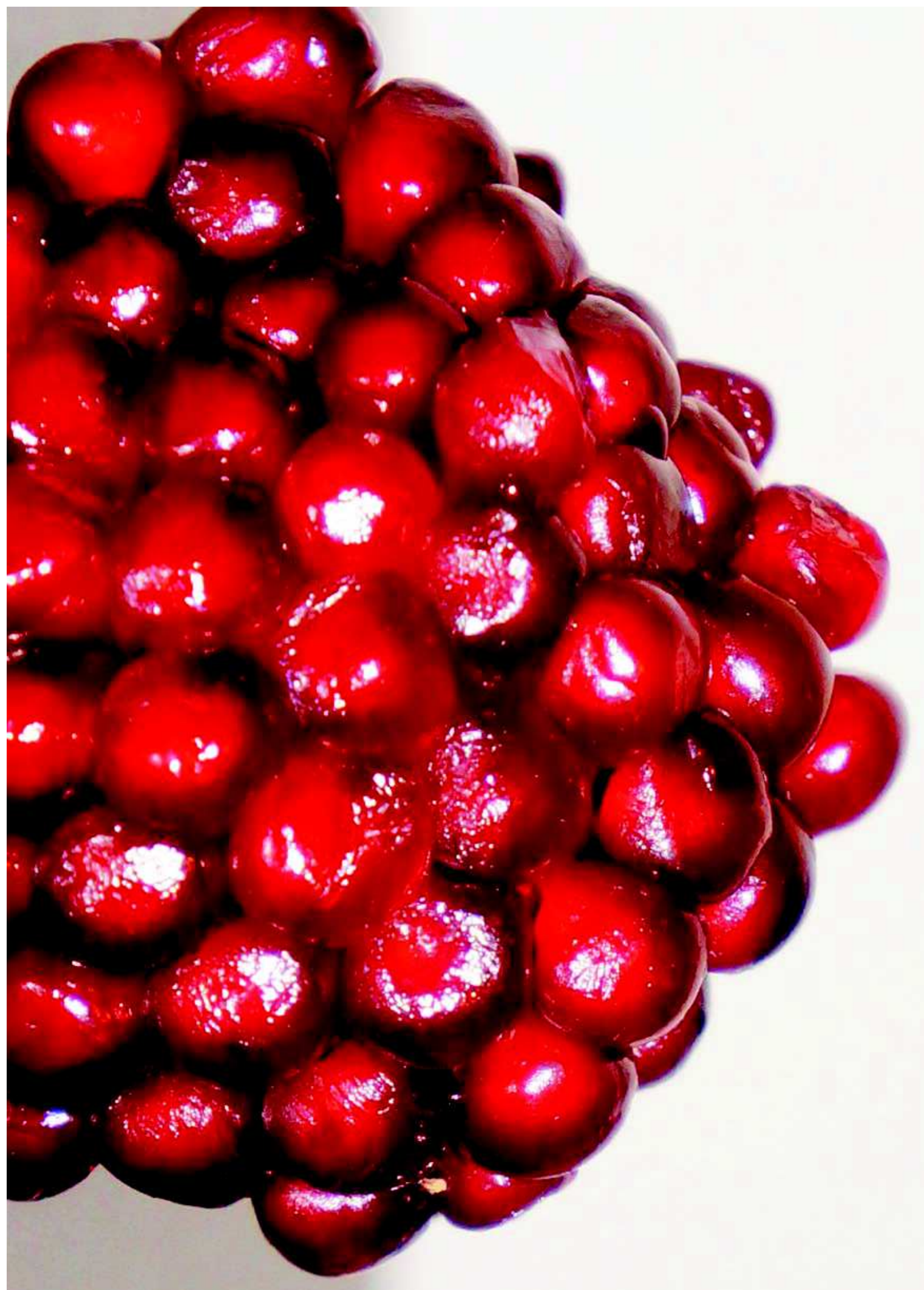




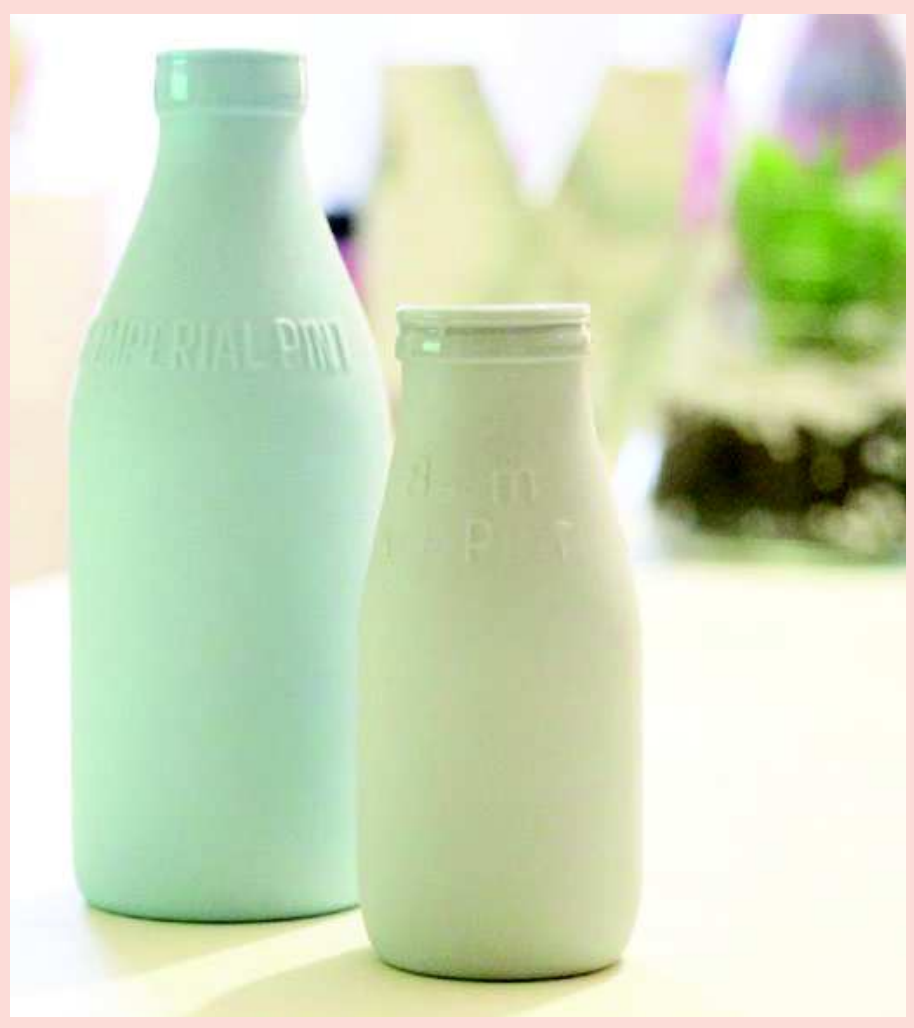

$>$ cer en profundidad los microorganismos así como los compuestos que sintetizan y metabolizan, porque las transformaciones que llevan a cabo en el zumo pueden ser beneficiosas".

Para introducir las bacterias en la bebida, los investigadores han empleado procedimientos de microencapsulación que permiten que los microorganismos sean más estables a su paso por el sistema gastrointestinal. "Cuando tomamos un yogur, muchas bacterias beneficiosas mueren en el camino pero ingerimos tantas que algunas llegan al colon", cuenta la profesora. Por este motivo, continúa, conseguir incrementar la supervivencia de los microorganismos hasta alcanzar el colon supone una ventaja saludable.

\section{Innovación alimentaria}

Los expertos han empleado matrices como el alginato para encapsular las bacterias -en forma de bolitas minúsculas- $y$ han simulado en el laboratorio el proceso de la digestión, desde que el alimento entra en contacto con los jugos gástricos hasta que las enzimas intestinales lo degradan. Con la recreación del recorrido

de la comida por el tracto gastrointestinal, se puede determinar la cantidad de bacterias que sobreviven al proceso. Se trata de un aspecto clave ya que, por ejemplo, las bacterias gastrointestinales intervienen, entre otros procesos, en la modificación bioquímica de polifenoles para que se puedan absorber y tener efectos beneficiosos.

La aceptación del consumidor es otro aspecto fundamental valorable a la hora de obtener un alimento nuevo. Aunque el tamaño de las microcápsulas incluidas en el zumo es mínimo, la doctora Frutos cuenta que no es necesario que pasen desapercibidas: "Si de esta forma conseguimos un producto más saludable, detectarlas puede formar parte de la experiencia sensorial".

La investigación en torno a las propiedades beneficiosas de los alimentos es un campo de trabajo multidisciplinar que requiere la interacción de profesionales de áreas como la Química, la Biología, la Ingeniería, la Nutrición, la Tecnología de Alimentos o la Bioquímica. La importancia de las colaboraciones entre grupos

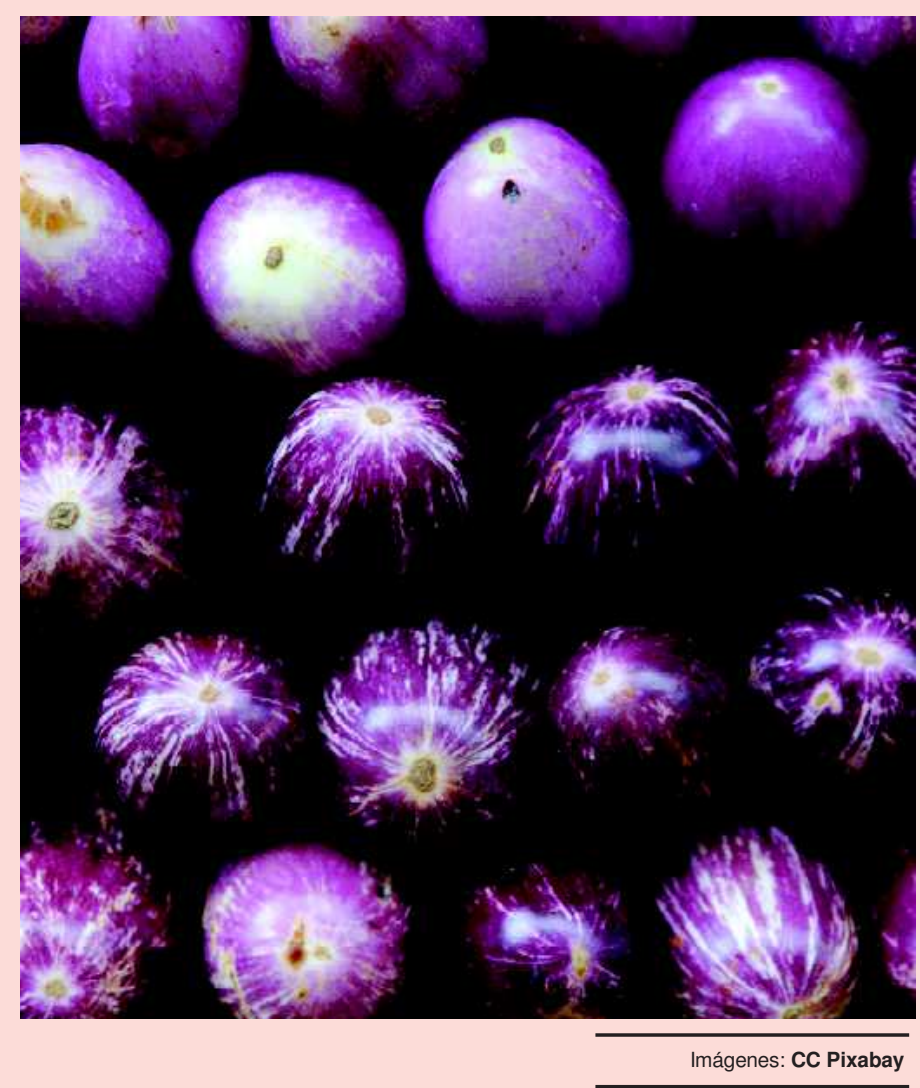

ha llevado a la UMH a trabajar con investigadores del equipo de Nutrición y Salud del Instituto AgResearch de Nueva Zelanda. En este país, se ha desarrollado el primer sistema de cultivo in vitro de células intestinales que lar las células cultivadas en un ambiente lo más similar posible al del organismo humano. "De esta manera, podremos conocer de forma exacta cómo se absorben los compuestos con los zumos fermentados", señala Frutos.

Aunque Europa dispone de herramientas como el European Food Information Council (EUFIC) para permite simu- informar a los consumidores sobre los avances en alimentación saludable, la investigadora de la UMH cree que sería positivo trasladar estas iniciativas a ámbitos más cercanos. Los planes de estudio escolares no incluyen formación acerca de los beneficios y las características de la comida, pero un mayor grado de conocimiento entre la población permitiría reducir algunas posiciones extremas y mejorar la alimentación y la salud de los compradores. "¿Por qué no aprovechar el tirón de los programas de cocina para incluir información sobre las características y los beneficios de la comida?", propone María José Frutos. 